\title{
Isolated Two Non-Displaced Coracoid Fracture Treated with Conservative Means: Report of Two Cases
}

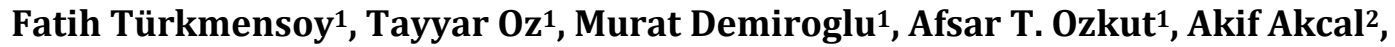 \\ Bulent Kilic ${ }^{3}$ \\ ${ }^{1}$ Istanbul Medeniyet University Goztepe Training and Research Hospital, Department of Orthopaedics and \\ Traumatology, Istanbul, Turkey \\ ${ }^{2}$ Department of Orthopedics and Traumalogy, Antalya Ataturk State Hospital, Antalya, Turkey \\ ${ }^{3}$ Gelisim University Health Sciences, Istanbul, Turkey \\ Email: turkmensoyfatih@gmail.com, tayyarozsefil@gmail.com, drmuratdemiroglu@gmail.com, \\ afsartozkut@gmail.com, mehmetakifakcal@yahoo.com, drbulentk@hotmail.com
}

Received 31 July 2015; accepted 29 August 2015; published 1 September 2015

Copyright (C) 2015 by authors and Scientific Research Publishing Inc.

This work is licensed under the Creative Commons Attribution International License (CC BY).

http://creativecommons.org/licenses/by/4.0/

c) (i) Open Access

\begin{abstract}
Coracoid fractures are usually seen with other shoulder injuries. Isolated fractures of this prominence are rare conditions. Herein we present two isolated coracoid fractures after a motorcycle accident and a fall onto the shoulder respectively. Conservative treatment with sling and passive-active shoulder exercises is accepted approach in these fractures. We also prefer conservative treatment at our cases and both of them have good results.
\end{abstract}

\section{Keywords}

Coracoid Fracture, Conservative Treatment, Shoulder Injuries

\section{Introduction}

The coracoid process is a small hook-like structure on the lateral edge of the superior anterior portion of the scapula. Coracoid fractures are uncommon injuries. Most have been reported to occur in adults and in association with acromioclavicular dislocation or anterior shoulder dislocation [1] [2]. The first reports of isolated coracoid fractures date as far back as 1907 [3]. These fractures constitute only 1\% of all fractures and 5\% of shoulder fractures [4]. The mechanism of injury to the coracoid is usually trauma, usually as a result of road traffic accident or with direct impact on the shoulder girdle [5]. We herein present two cases of an isolated frac-

How to cite this paper: Türkmensoy, F., Oz, T., Demiroglu, M., Ozkut, A.T., Akcal, A. and Kilic, B. (2015) Isolated Two Non-Displaced Coracoid Fracture Treated with Conservative Means: Report of Two Cases. Open Journal of Orthopedics, 5, 253-257. http://dx.doi.org/10.4236/ojo.2015.59034 
ture of the coracoid process in 34- and 11-year-old males and emphasise the importance of careful evaluation of the patient to detect these rare injuries.

\subsection{Case 1}

A 34-year-old male presented to our emergency room with left shoulder pain after a motorcycle accident. The pain was localised to the anterior aspect of the shoulder. He demonstrated only 90 degrees of active flexion and abduction with intense pain. A lesion suspected to be a coracoid fracture seen on an anteroposterior roentgenograph (Figure 1). The lesion was completely delineated by computed tomography (Figure 2). The patient was treated with analgesics and a simple arm sling for 3 weeks. During this period, passive shoulder exercises (mostly pendular) were performed. At the 3-week follow-up visit, the patient was symptom-free and active shoulder exercises were started. Follow-up X-rays at 3 months revealed evidence of bony union of the coracoid process. At the 6-month follow-up, he exhibited full range of motion with no symptoms.

\subsection{Case 2}

An 11-year-old male presented to our hospital following a fall onto the shoulder. Initially, direct radiographs showed no fractures. He also exhibited no neurovascular deficits. However, he reported intense pain localised to the anterior aspect of his shoulder. Computed tomography showed an isolated fracture of the base of the coracoid (Figure 3 and Figure 4). The patient was treated conservatively using a broad arm sling with analgesics for 3 weeks followed by active shoulder exercises. At 3 months, he was pain-free with a full range of motion.

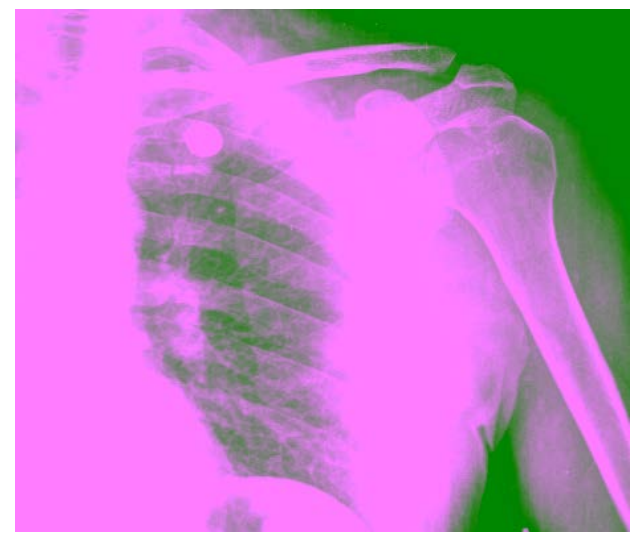

Figure 1. Anteroposterior roentgenograph of case 1. Fracture clear image in this roentgenograph is not available.
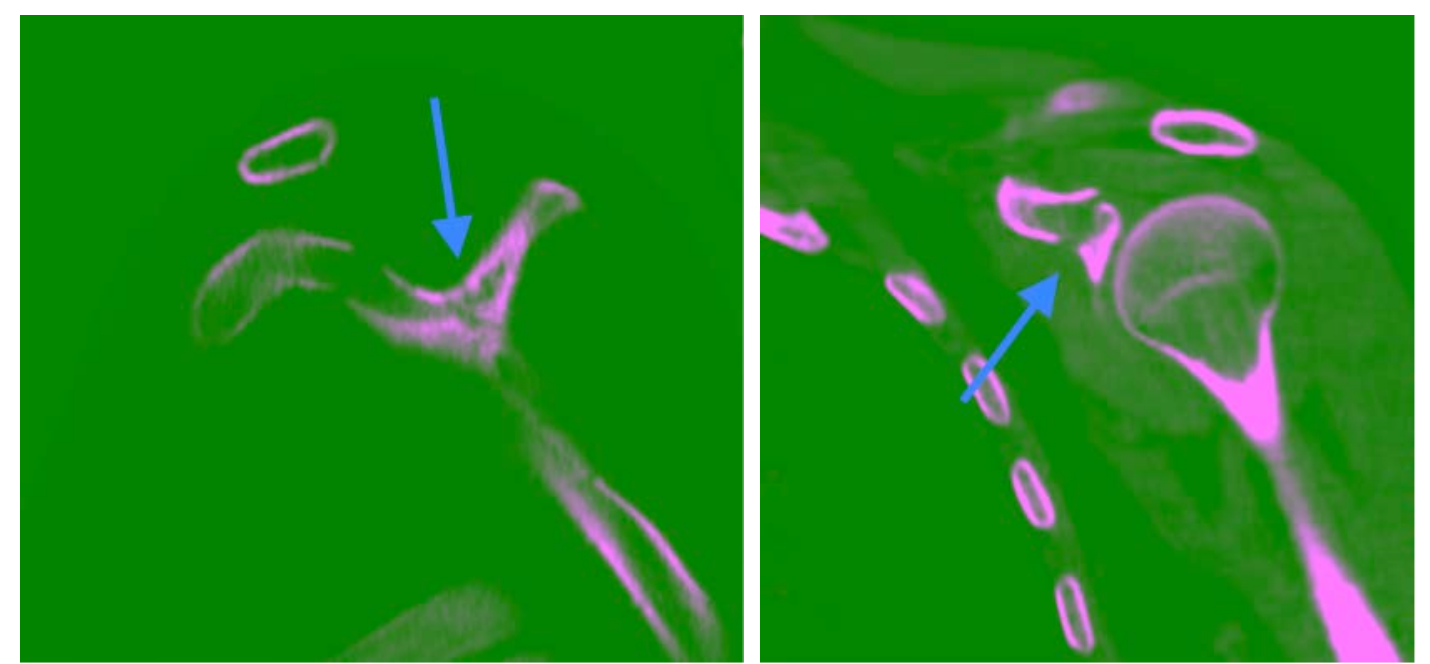

Figure 2. Computed tomography of case 1. 


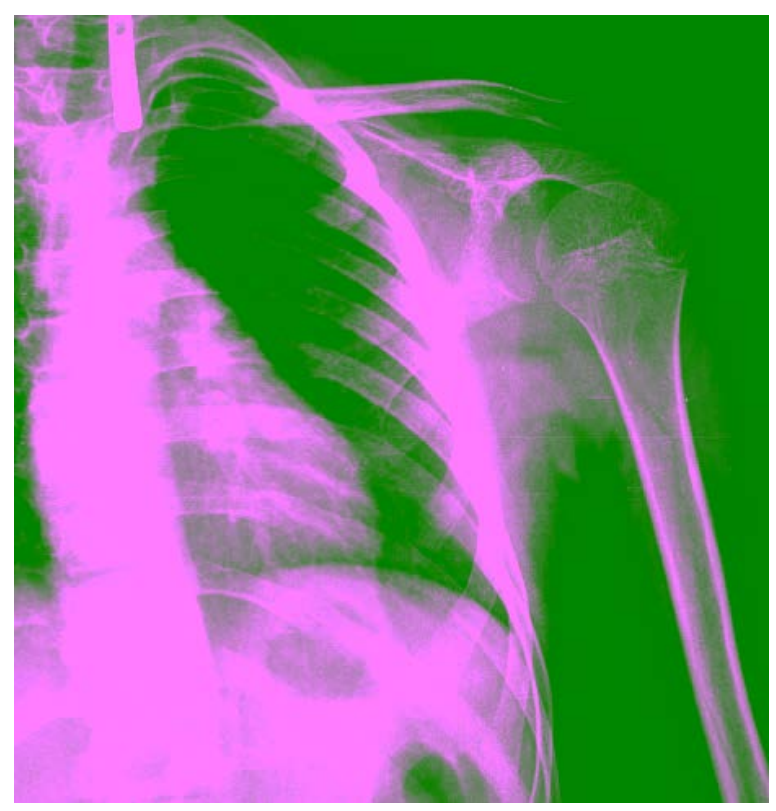

Figure 3. Anteroposterior roentgenograph of case 2. Fracture clear image in this roentgenograph is not available.
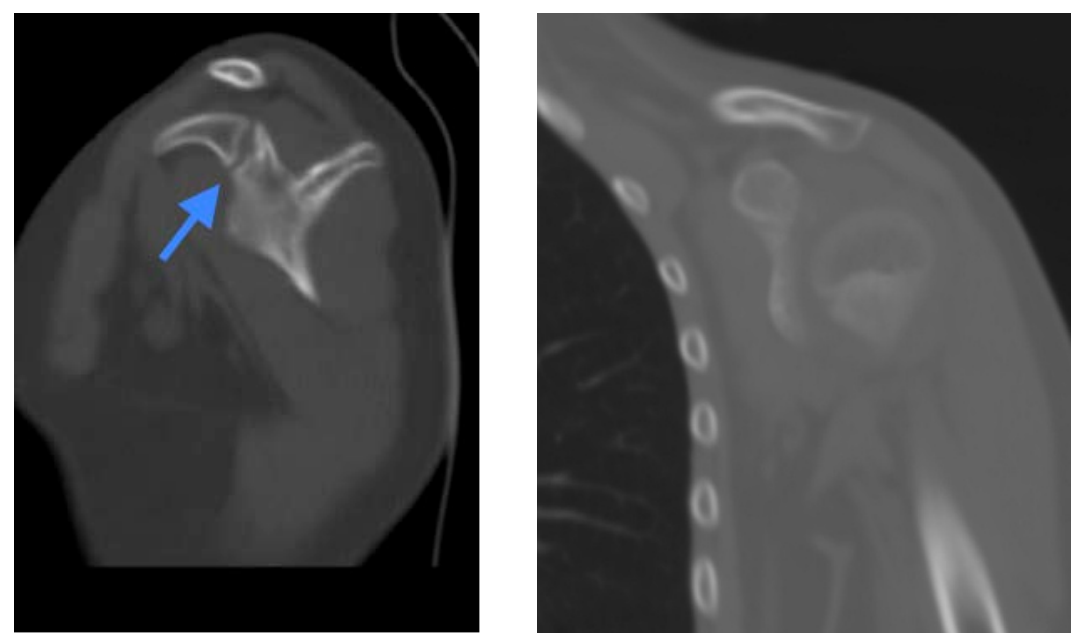

Figure 4. Computed tomography of case 2. Fracture was seen clearly in left CT section.

\section{Discussion}

Coracoid fractures can be isolated or associated with injury. Associated conditions include acromioclavicular disruption, clavicular fracture, acromial fracture, scapular spine fracture, and glenoid fracture [5] [6]. Isolated fractures of the coracoid appear to be rare. The available literature on these injuries seems to comprise mostly case reports. To date, only two cases of isolated coracoid fractures in skeletally immature patients have been reported in the English-language literature.

Ogawa et al. divide these fractures into five groups but recommend 2 groups based on according the neighborring coracoclavicular ligaments. Type II is the tip fracture, Type I is on the scapular side of the ligaments. Ogawa et al. suggest that these typeI fractures require operative fixation [5].

Standard anteroposterior and lateral scapular views do not readily demonstrate the base of coracoid fractures. Froimson described a technique in which the X-ray view is directed 45 degrees cephalad, which specifically displays the base of the coracoid. However, such a view is unlikely to be requested unless this rare diagnosis is considered [7]. Although this is an uncommon fracture, the authors recommend that an avulsion fracture be considered in patients with pain associated with the coracoid process upon palpation. Computed tomography or Fro- 
imson views should be ordered in these patients.

Based on our presented case reports, isolated fractures of the coracoid in the adolescent group can be treated successfully by conservative means. If any doubt that the presence of fractures or displacement amount we recommend that CT examination. Shoulder arm sling should be used to relieve pain and, more importantly, it should be used to prevent displacement. Do not hesitate CT examination because nondeplated fracture diagnosis should be missed. The treatment of an isolated coracoid process fracture depends on the location and displacement of the fracture. Nonoperative treatment of the fracture has been documented, especially when minimally displaced, as in our cases [5] [8] [9]. Most fractures occur at the base of the coracoid process, and displacement is usually minimal because the coracoclavicular ligaments tend to maintain the position of the fragments. The fracture surface is relatively large, and union can be expected even with comminution [5] [6]. Some authors have stated that coracoid fractures should be reduced when displacement is present or to prevent possible resultant disability. Serious displacement usually only occurs when the coracohumeral ligament or coracoclavicular ligament is torn [10]. Accepted indications for surgical treatment are painful nonunion, $>1-\mathrm{cm}$ displacement, concomitant scapula fracture, and superior shoulder suspensory complex injuries.

\section{Conclusions}

Operative treatment might not be necessary for isolated nondisplaced coracoid fractures because both of our patients had excellent results with a simple sling and early physiotherapy. Early physiotherapy includes pendular exercises for 3 weeks and active shoulder exercises thereafter. At 6 weeks, shoulder-strengthening exercises could be started.

Isolated coracoid fractures can easily be missed on plain roentgenographs, so physical examination combined with computed tomography in suspected cases is essential to diagnose these rare injuries in the emergency setting. It is also crucial to perform a detailed neurological examination because coracoid fractures, especially when displaced, can be associated with brachial plexus compression.

\section{Consent}

Informed consent was taken for this work.

\section{Conflict of Interests}

The authors declare that they have no conflict of interests.

\section{References}

[1] Lasda, N.A. and Murray, D.G. (1978) Fracture Separation of the Coracoid Process Associated with Acromioclavicular Dislocation. Clinical Orthopaedics and Related Research, 134, 222-224. http://dx.doi.org/10.1097/00003086-197807000-00036

[2] Benchetrit, E. and Friedman, B. (1979) Fracture of the Coracoid Process Associated with Subglenoid Dislocation of the Shoulder. A Case Report. The Journal of Bone and Joint Surgery, American Volume, 61, 295.

[3] Petty, O.H. (1907) Fracture of the Coracoid Process of the Scapula Caused by Muscular Action: With Report of Case. Annals of Surgery, 45, 427. http://dx.doi.org/10.1097/00000658-190703000-00008

[4] McGinnis, M. and Denton, J.R. (1989) Fractures of the Scapula: A Retrospective Study of 40 Fractured Scapulae. Journal of Trauma-Injury, Infection, and Critical Care, 29, 1488-1493. http://dx.doi.org/10.1097/00005373-198911000-00006

[5] Ogawa, K., Yoshida, A., Takahashi, M. and Ui, M. (1997) Fractures of the Coracoid Process. Journal of Bone \& Joint Surgery, British Volume, 79, 17-19. http://dx.doi.org/10.1302/0301-620X.79B1.6912

[6] Eyres, K., Brooks, A. and Stanley, D. (1995) Fractures of the Coracoid Process. Journal of Bone \& Joint Surgery, British Volume, 77, 425-428.

[7] Froimson, A. (1978) Fracture of the Coracoid Process of the Scapula. The Journal of Bone and Joint Surgery, American Volume, 60, 710.

[8] Ogawa, K., Inokuchi, S. and Matsui, K. (1990) Fracture of the Coracoid Process. Acta Orthopaedica Scandinavica, 61, 7-8. 
[9] Guiral, J., Real, J. and Curto, J. (1996) Isolated Fracture of the Coracoid Process of the Scapula. Acta Orthopaedica Belgica, 62, 60-61.

[10] Asbury, S. and Tennent, T. (2005) Avulsion Fracture of the Coracoid Process: A Case Report. Injury, 36, 567-568. http://dx.doi.org/10.1016/j.injury.2004.11.002 